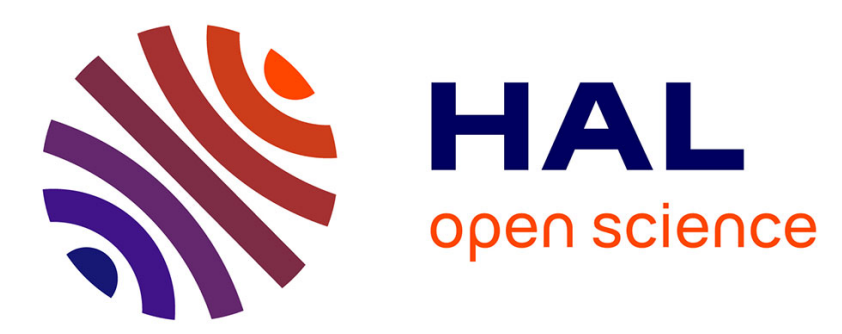

\title{
Accounting for the daily locations visited in the study of the built environment correlates of recreational walking (the RECORD Cohort Study)
}

\author{
Camille Perchoux, Yan Kestens, Ruben Brondeel, Basile Chaix
}

\section{- To cite this version:}

Camille Perchoux, Yan Kestens, Ruben Brondeel, Basile Chaix. Accounting for the daily locations visited in the study of the built environment correlates of recreational walking (the RECORD Cohort Study). Preventive Medicine, 2015, 81, pp.142-149. 10.1016/j.ypmed.2015.08.010 . hal-01198863

\section{HAL Id: hal-01198863 \\ https://hal.sorbonne-universite.fr/hal-01198863}

Submitted on 14 Sep 2015

HAL is a multi-disciplinary open access archive for the deposit and dissemination of scientific research documents, whether they are published or not. The documents may come from teaching and research institutions in France or abroad, or from public or private research centers.
L'archive ouverte pluridisciplinaire HAL, est destinée au dépôt et à la diffusion de documents scientifiques de niveau recherche, publiés ou non, émanant des établissements d'enseignement et de recherche français ou étrangers, des laboratoires publics ou privés. 
Accounting for the daily locations visited in the study of the built environment correlates of recreational walking (the RECORD Cohort Study)

Title: Accounting the daily locations visited in the study of the built environment correlates of recreational walking (the RECORD Cohort Study)

Authors names and affiliations: Camille Perchoux, M.Sc a,b,c,d; Yan Kestens, Ph.D c,d; Ruben Brondeel, M.Sc a,b, e; Basile Chaix, Ph.D a, b;

a Sorbonne Universités, UPMC Université Paris 06, UMR_S 1136, Institut Pierre Louis d'Epidémiologie et de Santé Publique, 75012, Paris, France b INSERM, UMR_S 1136, Institut Pierre Louis d'Epidémiologie et de Santé Publique, F75012, Paris, France

c Département de médecine sociale et préventive, Université de Montréal, Montreal (QC), Canada

d Centre de Recherche du Centre Hospitalier Universitaire de Montréal (CRCHUM), Montreal (QC), Canada

e Ecole des Hautes Etudes en Santé Publique (EHESP), 35043, Rennes, France

Corresponding author information: Camille Perchoux, INSERM, UMR_S 1136, Institut Pierre Louis d'Epidémiologie et de Santé Publique, 27 rue de Chaligny, 75012, Paris, France. Telephone number: +33 (0)1 447386 59, Email: camille.perchoux@ umontreal.ca

Word count: 3497

\section{Conflict of interest statement:}

Camille Perchoux has no conflict of interest.

Yan Kestens owns shares of Treksoft Solutions Inc., a company that markets and sells the VERITAS solution.

Ruben Brondeel has no conflict of interest.

Basile Chaix has no conflict of interest. 


\section{ABSTRACT}

Background: Understanding how built environment characteristics influence recreational walking is of the utmost importance to develop population-level strategies to increase levels of physical activity in a sustainable manner.

Purpose: This study analyses the residential and non-residential environmental correlates of recreational walking, using precisely geocoded activity space data.

Methods: The point-based locations regularly visited by 4,365 participants of the RECORD Cohort Study were collected between 2011 and 2013 in the Paris region using the VERITAS software (Visualization and Evaluation of Regular Individual Travel destinations and Activity Spaces). Zero-inflated negative binomial regressions were used to investigate associations between both residential and non-residential environmental exposure and overall self-reported recreational walking over 7 days.

Results: Density of destinations, presence of a lake or waterway, and neighborhood education were associated with an increase in the odds of reporting any recreational walking time. Only the density of destinations was associated with an increase in time spent walking for recreational purpose. Considering the recreational locations visited (i.e., sports and cultural destinations) in addition to the residential neighborhood in the calculation of exposure improved the model fit and increased the environment-walking associations, compared to a model accounting only for the residential space (Akaike Information Criterion equal to 52797 compared to 52815).

Conclusions: Creating an environment supportive to walking around recreational locations may particularly stimulate recreational walking among people willing to use these facilities.

Keywords: recreational walking, physical activity, built environment, activity space, urban area 


\section{INTRODUCTION}

Promoting higher levels of physical activity has become a public health priority $(1,2)$. During the past 15 years, there has been a growing interest in built environment characteristics that are supportive of walking when developing sustainable population-level strategies to increase levels of physical activity (3). Recent literature has emphasized that different types of interventions may be needed to promote walking for recreation and walking for transportation since findings suggest that different environmental characteristics are associated with these two components of walking (4-6).

Environmental characteristics such as land use mix $(7,8)$, residential density $(9,10)$, neighborhood educational level $(11,12)$, access to recreational and utilitarian destinations $(9$, 11, 13-15), access to greenness and public open spaces (11, 15-18), street connectivity (19), walking infrastructures $(7,8,20,21)$, and aesthetics and pleasant environmental features $(7$, 19-24) have been positively associated with recreational walking.

This available empirical evidence is mostly derived from studies exclusively focusing on the residential neighborhood. Usual representations of the exposure area to environmental conditions include administrative units or residence-centered buffers. These geographical home-centered definitions of exposure areas do not account for individual daily mobility and corresponding non-residential exposure $(25,26)$. The concept of activity space has been introduced in health research to emphasize that studies should consider the effects on health of both residential and non-residential environments (27-30). Findings for various outcomes suggest that activity space exposure may be more strongly associated with health than the traditional residential exposure measures (31-35). Studies accounting for daily mobility are becoming more common but remain scarce. One Australian study compared the associations between built environment characteristics and recreational walking when using both GPS 
locations and standard buffers to capture environmental characteristics and observed differences in associations depending on the spatial definition of the exposure area (36). Several mobility and health studies have used GPS data to examine the type of environments in which physical activity episodes occur (37-43). To our knowledge however, no study has investigated the associations of multiple environmental exposures within and outside the residential neighborhood with recreational walking.

The aims of the present study were i) to investigate associations between both residential and non-residential environmental exposure and recreational walking; and ii) to examine the effect of environmental conditions around each type of locations visited (workplace, services, recreational destinations, and social destinations) on recreational walking.

\section{MATERIAL AND METHODS}

\section{Study population}

The present study relied on data from the second wave of the RECORD Cohort Study (44). Overall, 5,542 participants were surveyed between February 2011 and October 2013. The participants were recruited without a priori sampling (convenience sample) during preventive checkups conducted by the Centre d'Investigations Préventives et Cliniques (IPC) located in Paris (45-52). Participants were living in one of 10 (out of 20) administrative divisions of Paris or 111 a priori selected municipalities of the Ile-de-France region in 2011-2013 or had been living in these municipalities in 2007-2008 during the recruitment of the cohort. In addition to the inclusion criteria of the RECORD Study (residence and age 30-79 in 20072008), the present analyses retained only participants residing in the Ile-de-France region who reported at least one non-residential destination (e.g., a workplace, a supermarket, etc.). The 
study protocol was approved by the French Data Protection Authority. All the participants signed an informed consent to enter the study.

\section{Assessment of participants' activity space}

Self-reported locations visited (i.e., the set of destinations visited by participants) were geocoded using the VERITAS software (29). The electronic questionnaire records the geographic location of the place of residence and of a series of other possible destinations regularly visited by the participants. Table 1 presents the reported destinations including the residence and various types of non-residential destinations. The associations between environmental exposures at multiple locations and recreational walking may be susceptible to the selective daily mobility bias $(29,53)$. Indeed, people choose the daily locations that they visit according to personal and intrapersonal characteristics (e.g., socio-demographic, psychological/cognitive, or behavioral characteristics). People who enjoy recreational walking tend to visit particular locations to have recreational walks. Determining the environmental exposures to correlate with recreational walking around such selected visited locations could introduce confounding if unmeasured intrapersonal characteristics have a causal effect on both the locations visited and the recreational walking behavior (53). This confounding bias stems from the fact that it is not the environmental conditions around these selected locations that encouraged participants to walk, but the willingness to walk that led to visit these locations to walk. Therefore, considering the exposure at the locations specifically visited to do recreational walking when calculating environmental exposures could lead to bias. Consequently, all the locations that were regularly visited to perform recreational walking where removed to determine the exposure areas of interest. We screened all the names of the reported locations visited to perform recreational activities and excluded all locations 
referring to "promenade", "walking", "walking with a dog", "brisk walking", "Nordic walking", and "hiking".

The exposure area around each visited location was computed as a street-network buffer with a radius size depending on the type of activity performed at the location. Since no information on the time spent at each visited location was available to weight the exposure accordingly, we attributed different radius sizes to the different groups of locations visited as an attempt to account for the varying exposure potential at the different types of locations. Larger buffer sizes were applied to visited locations where individuals are likely to spend more time and have more opportunity to explore the surroundings (29). Street network buffers of $1000 \mathrm{~m}$ were used around the residence and the workplace, $200 \mathrm{~m}$ around the services, and $500 \mathrm{~m}$ around both recreational and social activities.

Overall, six exposure areas were used: the residence space, the residence-work space - i.e., the combination of the residence and the work space -, the residence-service space, the residence-recreational space, the residence-social space (Figure 1), and finally a comprehensive exposure area encompassing all buffers around all reported visited locations, i.e. the total activity space. When combining areas, the potential overlap was suppressed.

\section{Measures}

\section{Recreational walking}

During their visit at the health center, in addition to the VERITAS questionnaire, the participants were invited to fill a computerized questionnaire on a PC tablet (both selfadministered and administered by a technician). Participants were asked to report retrospectively the overall number of hours and minutes they had walked over the previous seven days for leisure or exercise. To ensure that the participants were able to identify 
recreational walking and distinguish it from transport walking, examples of recreational walks were provided in the question, including taking a stroll or walking for exercise, alone or not, and with their pet or not. Participants were asked to report their recreational walking time done within or outside their residential neighborhood. To answer this question, the participants were asked to rely on their own definition of their neighborhood [no guidelines were provided to the participants (44), resulting in a self-defined residential neighborhood or subjective representation of neighborhood]. The present study considers the overall time of recreational walking, created by summing up the time reported inside and outside the residential neighborhood.

\section{Individual variables}

The following socio-demographic characteristics were considered for adjustment: age, sex, individual education (4 categories: no education and primary education, lower secondary education, higher secondary education and lower tertiary education, and upper tertiary education), employment status (4 categories: stable job, precarious job, unemployed, and retired), household income per consumption unit (tertiles: 1,222 and 2,125 euros/month), marital status (living alone or in a couple), and living with at least one child under the age of fourteen.

\section{Environmental variables}

Five environmental variables were determined. The density or proportion of area covered by green spaces derived from a 2008 geographic layer of the Institute of Urban Planning of the Ile-de-France Region (IAU-IDF); the density of destinations (number per $\mathrm{km}^{2}$ ) calculated 
using the 2011 Permanent Database of Facilities of the National Institute of Statistics and Economic Studies (INSEE) including information on administrations, public/private shops, health services, and entertainment facilities; the density of street intersections (number per $\mathrm{km}^{2}$ ) using the 2014 street network data from the National Geographic Institute; presence of a lake or a waterways determined from the 2003 IAU-IDF land use database; and neighborhood educational level defined as the proportion of residents with university education as obtained from the 2010 population census geocoded at the residential address by INSEE.

These environmental variables were computed within each of the six exposure areas described above, using Python scripts and ArcInfo 10.

\section{Statistical analyses}

To investigate the associations between the individual and environmental variables and recreational walking, we estimated zero-inflated negative binomial models (ZINB) $(54,55)$ using SAS 9.3. Recreational walking time can be considered as an over-dispersed count variable due to an excess of zeros (people who do not walk for recreation). Regular Poisson or negative binomial regression models are unable to handle correctly this kind of distributions. The ZINB regression consists of two parts: a zero-inflated part that models the odds of not reporting any recreational walking, with coefficients interpreted as odd ratios, and a count part that models recreational walking time among walkers, with coefficients interpreted as a percentage change.

The model building strategy involved seven steps. Model A included all individual sociodemographic variables. Model B to G included also the environmental variables for the following exposure areas: residence space (B), residence-work space (C), residence-service 
space (D), residence-recreational space (E), residence-social space (F), and total activity space (G). Akaike Information Criterion (AIC) are reported for each model (Tables 4 and 5).

\section{RESULTS}

\section{Description of the study sample}

From the initial available sample of 5487 participants living in the Ile-de-France region, we excluded 996 participants who regularly traveled outside the study area, 108 participants who regularly visited their secondary home, 3 participants with missing socio-demographic data and 15 participants with missing neighborhood education level data. The final study sample included 4365 adults. Descriptive information is provided in Table 2.

Overall, the median time of recreational walking over the previous 7 days was 180 minutes (interquartile range $=60,360$ ). Some 686 participants declared no recreational walking at all (16\%). The participants reported a median number of 13 distinct locations visited (interquartile range $=10 ; 16$ ) and a median number of 19 visits per week to all these locations (interquartile range $=13 ; 25)$. Summary statistics regarding the sizes of participants' activity spaces are provided in Table 3 .

\section{Associations between socio-demographic variables and recreational walking}

Associations between individual/environmental variables and the odds of not reporting any recreational walking (the zero-inflation part) are reported in Table 4. Associations between individual/environmental variables and the time spent walking among walkers (the count part) are reported in Table 5. Regarding the first part of the model, higher odds of not reporting any recreational walking were observed among participants with a low or middle low educational 
status. However, this relation disappeared when accounting for environmental characteristics. Being retired decreased the odds of not reporting any recreational walking time by $43 \%$, compared to participants with a stable employment status.

As show in Table 5, among recreational walkers, being a male, having a low or middle low individual education, having a precarious employment status, being unemployed, or being retired were associated with an increase in recreational walking time, while living with at least one child under the age of fourteen was associated with a $11 \%$ decrease in recreational walking time. These associations were stable when accounting for residential and/or nonresidential environmental variables.

\section{Associations between residential neighborhood variables and recreational walking}

After controlling for individual characteristics, the odds of not reporting any recreational walking time was lower for participants living in neighborhoods with a lake or a waterway $[\mathrm{OR}=0.84 ; 95 \%$ confidence interval $(\mathrm{CI}): 0.71-0.99]$, with medium $(\mathrm{OR}=0.81 ; 95 \% \mathrm{CI}$ :

$0.66-0.99)$ or high $(\mathrm{OR}=0.62 ; 95 \% \mathrm{CI}: 0.49-0.79)$ density of destinations as opposed to low, and with a high educational level (OR $=0.72 ; 95 \%$ CI: $0.56-0.93)$ (Table 4).

As shown in Table 5, only the density of destinations was associated with the time spent walking among recreational walkers. Compared to low density neighborhoods, the time of walking increased by $14 \%$ in medium, and by $22 \%$ in high density neighborhoods. 


\section{Associations between activity space environmental variables and recreational walking}

Models $\mathrm{C}$ to $\mathrm{F}$ are interested in the effect of adding to the residential space, separately the work space (C), the service space (D), the recreational space (E) and the social space (F), and of adding all of these visited locations $(G)$ in the definition of environmental exposures.

The AIC was higher - thus the fit of the model poorer - in the models considering the work space, the service space, and the social space in addition to the residential environment in the definition of the exposures. The fit of the model was better in the model considering the recreational space in addition to the residential space. Model fit was slightly better in the model considering the full activity space.

In addition to the drop in AIC, differences in the strength of the associations were observed according to the definition of the exposure area. Regarding the odds of not reporting any recreational walking (Table 4), the association with the presence of a lake or waterway disappeared in all models, except in the model accounting for the residence-recreational space. The association between the density of destinations and the odds of not reporting any recreational walking was stronger in the residence-recreational space than in the model with residential variables only (and to a lesser extent in the model considering the full activity space).

Regarding the other part of the model (Table 5), the recreational walking time among walkers remained associated with the density of destinations when considering the non-residential spaces. The association was only slightly stronger in the model for the residence-recreational space. 


\section{DISCUSSION}

Overall, a high density of destinations, the presence of a lake or waterway, and a high neighborhood education were associated with higher odds of recreational walking, while a high density of destinations was also associated with a higher amount of recreational walking time. Accounting for exposure to environmental factors in the recreational locations visited improved the prediction of the odds to undertake recreational walking and of the walking time. Accounting for other locations visited (workplace, services, social activity locations) did not contribute.

When accounting for the residential neighborhood only, the presence of a lake or a waterway was associated with reporting any recreational walking, while no association was found with time of recreational walking. This is in line with a study in Australia that showed a positive association between access to the beach and the likelihood of walking for recreation (22). Similarly, the association between neighborhood education and recreational walking is consistent with previous research $(11,12,21)$. The observed positive association between the density of destinations and both reporting and total time spend in recreational walking confirms our hypothesis and is in line with previous studies $(5,9,19,49,56)$.

No effect of accessibility to green spaces was observed, but findings on this topic are mixed. Some have reported positive associations (16-18), including a previous study based on the first wave of the RECORD Cohort Study (11), while others have reported null findings (22, 57). A recent review on the subject reported that $44 \%$ of the studies found associations between green spaces and recreational walking (5). Interestingly, a longitudinal study found green spaces to be associated with the maintenance of recreational walking but not with its initiation (58). 
When accounting for both residential and non-residential environments, the odds of walking were no longer associated with the presence of a lake or a waterway, while the other associations were fairly stable. The odds of reporting no recreational walking remained associated with the density of destinations and with neighborhood education while the recreational walking time remained associated with the density of destinations.

The aim of this study was to analyze the contribution of environmental factors in different portions of the activity space on recreational walking. Based on the strengths of associations and on the indicator of model fit, taking into account the geographic space around the regular recreational locations improved the prediction of walking for recreation and of the time spent walking. Yet, accounting for other types of locations visited did not improve the model performances, including when considering the geographic work environment, where workers spend a significant part of their time. This may be due to the fact that people have little time for recreational walking around their work schedule. Similarly, considering the geographic environment around participants' supermarkets may be less important when investigating recreational walking because people typically carry heavy bags. Conversely, the practice of recreational activities might imply less physical or time constraints, and people might be more likely or desirous of having a recreational walk in this context. This result suggests that measures of exposure around visited locations should not only consider where people go (the location of these places) and the corresponding environmental characteristics, but should also account for what they actually do and the constraints associated with the activity performed.

The significant role of environmental factors around the recreational locations visited suggest that improving walkability around such settings may be effective to increase recreational walking among people using such facilities. For example, people may walk for recreation before or after their activity when going to the tennis court or swimming pool if the surrounding environment is favorable. Promoting a walking-friendly environment around 
recreational locations could result in additional recreational walking, and may have for example a stronger beneficial influence than a walking-friendly environment around other destinations such as supermarkets.

Another interpretation however, may be that the drop in AIC and slight increase in the strength of associations was attributable, not to an effect of these recreational environments, but to the fact that, despite the exclusion of locations visited for recreational walking, some of these recreational locations were specifically visited to do recreational walking (residual selective daily mobility bias). According to this hypothesis, the observed increase in the associations would be attributable to the fact that with these locations we identify people with specific interest and preferences for recreational activities including recreational walking. The increase in effect size and fit would then be due to a causal effect of preferences and values rather than to a causal effect of environmental conditions $(29,53)$.

Assuming that the patterns of associations reported reflect causal effects of the environments (which our cross-sectional study cannot firmly establish), our results also suggest that when accounting for daily mobility in health studies, all types of visited locations do not equally contribute to the understanding of neighborhood effects on health. Considering some of these locations may add noise to the environmental measures of interest, with the type of visited locations adding noise depending on the outcome (e.g., the workplace when investigating recreational walking).

\section{Strengths and limitations}

The main limitation of the study is its cross-sectional design. It prevented us from taking into consideration residential neighborhood self-selection. A recent systematic review emphasized that studies show an attenuation of the association between built environment characteristics 
and physical activity when accounting for neighborhood self-selection (3), calling for more experimental or quasi-experimental designs to isolate the effect of the built environment on walking behavior. Finally, we acknowledge that our analyses should be replicated with other population samples and by considering other environmental factors (e.g., air quality and noise, social-interactional processes, etc.). We also emphasize that it would be relevant to perform comparative analyses of recreational and transportation walking considering residential and non-residential environments, to evaluate the extent to which urban planning interventions may have consistent effects on the different components of walking behavior.

A strength of our study is the large sample size with precise geocoding of the visited locations. For each visited location, the nature of the activity performed was known. Based on this information, this study is one of the first to address the selective daily mobility bias by excluding locations that were specifically visited to do recreational walking. Ignoring this generally leads to an over-estimation of the associations between environmental characteristics and health behaviors $(29,53)$. Another strength is the operationalization of our activity space exposure measures to assess the specific contribution of each portion of the activity space.

\section{CONCLUSION}

In conclusion, exploring the potential contributions of different portions of the activity space to environmental influences on walking supports the idea that it is useful to take into account non-residential environments when investigating contextual determinants of recreational walking. Taking into account the environment around the recreational locations visited contributed to a better understanding of environmental effects on recreational walking. Finally, our findings contribute to suggest that creating supportive built environments around 
the residence could stimulate recreational walking. A complementary place-based intervention, which will have to be evaluated using experimental or quasi-experimental designs, would be to create supportive environments around recreational destinations like sport and cultural facilities in the Paris metropolitan area, to increase recreational walking among people using or traveling to these facilities.

\section{ACKNOWLEDGMENTS}

The VERITAS project, as related to the RECORD Study, is supported by the Institute for Public Health Research (IReSP, Institut de Recherche en Santé Publique); the National Institute for Prevention and Health Education (INPES, Institut National de Prévention et d'Education pour la Santé) (Prevention Program 2007; 2010-2011 financial support; and 2011-2013 financial support); the National Institute of Public Health Surveillance (InVS, Institut de Veille Sanitaire) (Territory and Health Program); the French Ministries of Research and Health (Epidemiologic Cohorts Grant 2008); the National Health Insurance Offıce for Salaried Workers (CNAM-TS, Caisse Nationale d'Assurance Maladie des Travailleurs Salariés); the Ile-de-France Regional Health Agency (ARS, Agence Régionale de Santé d'Île-de-France); the City of Paris (Ville de Paris); the Ile-de-France Regional Council (Conseil Régional d'Île-de-France, DIM SEnT and CODDIM); and the Ile-de-France Youth, Sports, and Social Cohesion Regional Direction (DRJSCS, Direction Régionale de la Jeunesse et des Sports et de la Cohésion Sociale). The VERITAS project is also supported by the Canadian Institutes for Health Research (CIHR No. TOO-105427). This work was supported by the Canadian Institute of Health Research (Grant \# 213338). Basile Chaix is supported by the National Institure of Health and Medical Research (INSERM, Institut National de la Santé et de la Recherche Médicale). Ruben Brondeel is supported by a grant from the EHESP School of Public Health (Ecole des Hautes Etudes en Santé Publique). Yan Kestens is supported by an investigator award from the Fonds de Recherche en Santé du Québec (FRSQ). 


\section{REFERENCES}

1. Haskell WL, Blair SN, Hill JO. Physical activity: health outcomes and importance for public health policy. Preventive Medicine. 2009;49(4):280-2.

2. Haskell WL, Lee I-M, Pate RR, Powell KE, Blair SN, Franklin BA, et al. Physical activity and public health: updated recommendation for adults from the American College of Sports Medicine and the American Heart Association. Circulation. 2007;116(9):1081.

3. McCormack GR, Shiell A. In search of causality: a systematic review of the relationship between the built environment and physical activity among adults. International Journal of Behavioral Nutrition and Physical Activity. 2011;8(125):10.1186.

4. Owen N, Humpel N, Leslie E, Bauman A, Sallis JF. Understanding environmental influences on walking. American journal of preventive medicine. 2004;27(1):67-76.

5. Sugiyama T, Neuhaus M, Cole R, Giles-Corti B, Owen N. Destination and route attributes associated with adults' walking: a review. Medicine and science in sports and exercise. 2012;44(7):1275-86.

6. Saelens BE, Handy SL. Built environment correlates of walking: a review. Medicine and science in sports and exercise. 2008;40(7 Suppl):S550.

7. Van Dyck D, Cerin E, Conway TL, De Bourdeaudhuij I, Owen N, Kerr J, et al. Perceived neighborhood environmental attributes associated with adults' leisure-time physical activity: findings from Belgium, Australia and the USA. Health \& place. 2013;19:59-68.

8. Bourdeaudhuij ID, Teixeira PJ, Cardon G, Deforche B. Environmental and psychosocial correlates of physical activity in Portuguese and Belgian adults. Public Health Nutrition. 2005;8(07):886-95.

9. Coogan PF, White LF, Adler TJ, Hathaway KM, Palmer JR, Rosenberg L. Prospective study of urban form and physical activity in the Black Women's Health Study. American Journal of Epidemiology. 2009;170(9):1105-17.

10. Van Dyck D, Cardon G, Deforche B, Sallis JF, Owen N, De Bourdeaudhuij I. Neighborhood SES and walkability are related to physical activity behavior in Belgian adults. Preventive medicine. 2010;50:S74-S9.

11. Chaix B, Simon C, Charreire H, Thomas F, Kestens Y, Karusisi N, et al. The environmental correlates of overall and neighborhood based recreational walking (a cross-sectional analysis of the RECORD Study). International journal of behavioral nutrition and physical activity. 2014;11(1):20.

12. Leslie E, Cerin E, Kremer P. Perceived neighborhood environment and park use as mediators of the effect of area socio-economic status on walking behaviors. Journal of physical activity \& health. 2010;7(6):802-10.

13. De Greef K, Van Dyck D, Deforche B, De Bourdeaudhuij I. Physical environmental correlates of self-reported and objectively assessed physical activity in Belgian type 2 diabetes patients. Health and Social Care in the Community. 2011;19(2):178-88.

14. Van Cauwenberg J, Clarys P, De Bourdeaudhuij I, Van Holle V, Verté D, De Witte N, et al. Physical environmental factors related to walking and cycling in older adults: the Belgian aging studies. BMC public health. 2012;12(1):142.

15. Charreire H, Weber C, Chaix B, Salze P, Casey R, Banos A, et al. Identifying built environmental patterns using cluster analysis and GIS: Relationships with walking, cycling and body mass index in French adults. Int J Behav Nutr Phys Act. 2012;9:59.

16. Sugiyama T. The Built Environment and Physical Activity Behaviour Change: New Directions for Research? : Japanese Association of Exercise Epidemiology; 2012.

17. Sugiyama T, Francis J, Middleton NJ, Owen N, Giles-Corti B. Associations between recreational walking and attractiveness, size, and proximity of neighborhood open spaces. Journal Information. 2010;100(9).

18. Giles-Corti B, Broomhall MH, Knuiman M, Collins C, Douglas K, Ng K, et al. Increasing walking: how important is distance to, attractiveness, and size of public open space? American journal of preventive medicine. 2005;28(2 Suppl 2):169. 
19. Cleland VJ, Timperio A, Crawford D. Are perceptions of the physical and social environment associated with mothers' walking for leisure and for transport? A longitudinal study. Preventive Medicine. 2008;47(2):188-93.

20. Lee C, Moudon AV. Correlates of walking for transportation or recreation purposes. Journal of Physical Activity \& Health. 2006;3:S77.

21. Ball K, Bauman A, Leslie E, Owen N. Perceived environmental aesthetics and convenience and company are associated with walking for exercise among Australian adults. Preventive medicine. 2001;33(5):434-40.

22. Giles-Corti B, Donovan RJ. Socioeconomic status differences in recreational physical activity levels and real and perceived access to a supportive physical environment. Preventive Medicine. 2002;35(6):601-11.

23. Ball K, Timperio A, Salmon J, Giles-Corti B, Roberts R, Crawford D. Personal, social and environmental determinants of educational inequalities in walking: a multilevel study. Journal of Epidemiology and Community Health. 2007;61(2):108-14.

24. Inoue S, Ohya Y, Odagiri Y, Takamiya T, Kamada M, Okada S, et al. Perceived neighborhood environment and walking for specific purposes among elderly Japanese. Journal of epidemiology/Japan Epidemiological Association. 2010;21(6):481-90.

25. Chaix B, Merlo J, Evans D, Leal C, Havard S. Neighbourhoods in eco-epidemiologic research: delimiting personal exposure areas. A response to Riva, Gauvin, Apparicio and Brodeur. Soc Sci Med. 2009;69(9):1306-10. Epub 2009/08/21.

26. Cummins S. Commentary: investigating neighbourhood effects on health--avoiding the 'local trap'. Int J Epidemiol. 2007;36(2):355-7. Epub 2007/03/23.

27. Chaix B, Méline J, Duncan S, Jardinier L, Perchoux C, Vallée J, et al. Neighborhood environments, mobility, and health: Towards a new generation of studies in environmental health research. Revue d'Épidémiologie et de Santé Publique. 2013;61, Supplement 3(0):S139-S45.

28. Perchoux C, Chaix B, Cummins S, Kestens Y. Conceptualization and measurement of environmental exposure in epidemiology: Accounting for activity space related to daily mobility. Health \& Place. 2013;21(0):86-93.

29. Chaix B, Kestens Y, Perchoux C, Karusisi N, Merlo J, Labadi K. An interactive mapping tool to assess individual mobility patterns in neighborhood studies. Am J Prev Med. 2012;43(4):440-50. Epub 2012/09/21.

30. Matthews SA, Yang T-C. Spatial Polygamy and Contextual Exposures (SPACEs): Promoting Activity Space Approaches in Research on Place And Health. American Behavioral Scientist. 2013:0002764213487345.

31. Inagami S, Cohen DA, Finch BK. Non-residential neighborhood exposures suppress neighborhood effects on self-rated health. Soc Sci Med. 2007;65(8):1779-91. Epub 2007/07/07.

32. Setton E, Marshall JD, Brauer M, Lundquist KR, Hystad P, Keller P, et al. The impact of daily mobility on exposure to traffic-related air pollution and health effect estimates. J Expo Sci Environ Epidemiol. 2011;21(1):42-8. Epub 2010/07/01.

33. Kestens $Y$, Lebel A, Chaix B, Clary C, Daniel M, Pampalon R, et al. Association between Activity Space Exposure to Food Establishments and Individual Risk of Overweight. PLoS ONE. 2012;7(8):e41418.

34. Lebel A, Kestens $Y$, Pampalon R, Thériault M, Daniel M, Subramaniam SV. Local context influence, activity space, and foodscape exposure in two Canadian metropolitan settings: Is daily mobility exposure associated with overweight? Journal of obesity. 2012.

35. Shareck M, Kestens $\mathrm{Y}$, Frohlich KL. Moving beyond the residential neighborhood to explore social inequalities in exposure to area-level disadvantage: Results from the Interdisciplinary Study on Inequalities in Smoking. Social Science \& Medicine. 2014;108:106-14.

36. Boruff BJ, Nathan A, Nijënstein S. Using GPS technology to (re)-examine operational definitions of 'neighbourhood'in place-based health research. International journal of health geographics. 2012;11(1):22. 
37. Cooper AR, Page AS, Wheeler BW, Hillsdon M, Griew P, Jago R. Research Patterns of GPS measured time outdoors after school and objective physical activity in English children: the PEACH project. 2010.

38. Troped PJ, Wilson JS, Matthews CE, Cromley EK, Melly SJ. The Built Environment and Location-Based Physical Activity. American Journal of Preventive Medicine. 2010;38(4):429-38.

39. Maddison R, Jiang Y, Vander Hoorn S, Exeter D, Ni Mhurchu C, Dorey E. Describing patterns of physical activity in adolescents using global positioning systems and accelerometry. Pediatric exercise science. 2010;22(3):392.

40. Quigg R, Gray A, Reeder Al, Holt A, Waters DL. Using accelerometers and GPS units to identify the proportion of daily physical activity located in parks with playgrounds in New Zealand children. Preventive medicine. 2010;50(5):235-40.

41. Rodríguez DA, Cho G-H, Evenson KR, Conway TL, Cohen D, Ghosh-Dastidar B, et al. Out and about: Association of the built environment with physical activity behaviors of adolescent females. Health \&amp; Place. 2012;18(1):55-62.

42. Wheeler BW, Cooper AR, Page AS, Jago R. Greenspace and children's physical activity: a GPS/GIS analysis of the PEACH project. Preventive medicine. 2010;51(2):148-52.

43. Evenson KR, Wen F, Hillier A, Cohen DA. Assessing the contribution of parks to physical activity using global positioning system and accelerometry. Medicine and science in sports and exercise. 2013;45(10):1981-7.

44. Chaix B, Kestens Y, Bean K, Leal C, Karusisi N, Meghiref K, et al. Cohort Profile: Residential and non-residential environments, individual activity spaces and cardiovascular risk factors and diseases-The RECORD Cohort Study. International Journal of Epidemiology. 2011.

45. Chaix B, Bean K, Leal C, Thomas F, Havard S, Evans D, et al. Individual/Neighborhood Social Factors and Blood Pressure in the RECORD Cohort Study Which Risk Factors Explain the Associations? Hypertension. 2010;55(3):769-75.

46. Leal C, Bean K, Thomas F, Chaix B. Are Associations Between Neighborhood Socioeconomic Characteristics and Body Mass Index or Waist Circumference Based on Model Extrapolations? Epidemiology. 2011;22(5):694-703.

47. Chaix B, Jouven X, Thomas F, Leal C, Billaudeau N, Bean K, et al. Why socially deprived populations have a faster resting heart rate: impact of behaviour, life course anthropometry, and biology-the RECORD Cohort Study. Social Science and Medicine. 2011;73(10):1543-50.

48. Karusisi N, Bean K, Oppert J-M, Pannier B, Chaix B. Multiple dimensions of residential environments, neighborhood experiences, and jogging behavior in the RECORD Study. Preventive Medicine. 2012;55(1):50-5.

49. Karusisi N, Thomas F, Méline J, Brondeel R, Chaix B. Environmental conditions around itineraries to destinations as correlates of walking for transportation among adults: the RECORD cohort study. PloS one. 2014;9(5):e88929.

50. Karusisi N, Thomas F, Méline J, Chaix B. Spatial accessibility to specific sport facilities and corresponding sport practice: the RECORD Study. International Journal of Behavioral Nutrition and Physical Activity. 2013;10(1):48.

51. Lewin A, Pannier B, Méline J, Karusisi N, Thomas F, Chaix B. Residential neighborhood, geographic work environment, and work economic sector: associations with body fat measured by bioelectrical impedance in the RECORD Study. Annals of Epidemiology. 2014;24(3):180-6.

52. Perchoux C, Kestens Y, Thomas F, Van Hulst A, Thierry B, Chaix B. Assessing patterns of spatial behavior in health studies: Their socio-demographic determinants and associations with transportation modes (the RECORD Cohort Study). Social Science and Medicine. 2014;119:64-73.

53. Chaix B, Méline J, Duncan S, Merrien C, Karusisi N, Perchoux C, et al. GPS tracking in neighborhood and health studies: A step forward for environmental exposure assessment, a step backward for causal inference? Health \& Place. 2013;21(0):46-51.

54. Vettenburg N, Brondeel R, Gavray C, Pauwels L. Societal vulnerability and adolescent offending: The role of violent values, self-control and troublesome youth group involvement. European Journal of Criminology. 2013;10(4):444-61. 
55. De Smet O, Buysse A, Brondeel R. Effect of the Breakup Context on Unwanted Pursuit Behavior Perpetration Between Former Partners. Journal of Forensic Sciences. 2011;56(4):934-41. 56. McCormack GR, Giles-Corti B, Bulsara M. The relationship between destination proximity, destination mix and physical activity behaviors. Preventive Medicine. 2008;46(1):33-40.

57. Zlot Al, Schmid TL. Relationships among community characteristics and walking and bicycling for transportation or recreation. american Journal of health Promotion. 2005;19(4):314-7.

58. Sugiyama T, Giles-Corti B, Summers J, du Toit L, Leslie E, Owen N. Initiating and maintaining recreational walking: A longitudinal study on the influence of neighborhood green space. Preventive medicine. 2013;57(3):178-82. 
Table 1. Types of locations visited geolocated in VERITAS and related sizes of the street network buffer for assessing environmental exposures, (the RECORD Cohort study, 20112013)

\begin{tabular}{|c|c|c|}
\hline Locations visited & Frequency of visit $^{\mathrm{a}}$ & $\begin{array}{l}\text { Size of the street network } \\
\text { buffer }\end{array}$ \\
\hline \multicolumn{3}{|l|}{ Domain : Residence } \\
\hline Place of residence & N/A & $1000 \mathrm{~m}$ \\
\hline Another address where the participant & At least once a & $1000 \mathrm{~m}$ \\
\hline \multicolumn{3}{|l|}{ Domain: Work } \\
\hline Workplace & At least once a week & $1000 \mathrm{~m}$ \\
\hline \multicolumn{3}{|l|}{ Domain: Services } \\
\hline Supermarket & At least once a month & $200 \mathrm{~m}$ \\
\hline Outdoor market & At least once a week & $200 \mathrm{~m}$ \\
\hline Bakery & At least once a week & $200 \mathrm{~m}$ \\
\hline Butcher & At least once a week & $200 \mathrm{~m}$ \\
\hline Fruits and vegetables shop & At least once a week & $200 \mathrm{~m}$ \\
\hline Fish shop & At least once a week & $200 \mathrm{~m}$ \\
\hline Cheese merchant & At least once a week & $200 \mathrm{~m}$ \\
\hline Specific food store & eek & $200 \mathrm{~m}$ \\
\hline Tobacco shop / Press shop & At least once a week & $200 \mathrm{~m}$ \\
\hline Bank & Most often used & $200 \mathrm{~m}$ \\
\hline Post office & Most often used & $200 \mathrm{~m}$ \\
\hline Hair dresser & Most often used & $200 \mathrm{~m}$ \\
\hline \multicolumn{3}{|l|}{ Domain: Transport } \\
\hline $\begin{array}{l}\text { Transportation station used from } \\
\text { home }\end{array}$ & At least once a week & $200 \mathrm{~m}$ \\
\hline \multicolumn{3}{|l|}{ Domain: Recreational activities } \\
\hline Sports facilities & At least once a week & $500 \mathrm{~m}$ \\
\hline Place of cultural activity & At least once a week & $500 \mathrm{~m}$ \\
\hline $\begin{array}{l}\text { Place of syndical, political, or } \\
\text { religious activity }\end{array}$ & At least once a week & $500 \mathrm{~m}$ \\
\hline \multicolumn{3}{|l|}{ Domain: Social activities } \\
\hline $\begin{array}{l}\text { Place of social activities (bar, } \\
\text { restaurant, cinema...) }\end{array}$ & At least once a week & $500 \mathrm{~m}$ \\
\hline Place where participants take relatives & At least once a week & $500 \mathrm{~m}$ \\
\hline Places where participants visit people & At least once a week & $500 \mathrm{~m}$ \\
\hline
\end{tabular}

\footnotetext{
a No particular recall period, such as "over the past 6 months," was specified over which participants were asked to recall their activities. This approach allowed us to ask people to report their "current regular behavior" (e.g., over the last 6 months if a participant just moved in her/his current neighborhood, or over a longer period for participants residing for a longer time in their neighborhood). These self-reported destinations were geocoded if they were visited at least once a week, or at least once a month for supermarkets, or regardless of the frequency of visit for the banks, post offices, and hairdressers.
} 
Table 2. Descriptive information on the sample used in the study based on the RECORD Cohort (2011-2013), N=4365

\begin{tabular}{lll}
\hline Variable & Category & $\begin{array}{l}\% \text { or } \\
\text { mean }\end{array}$ \\
\hline Sex (\%) & & 33 \\
Age (mean, years) & Female & 53 \\
Citizenship (\%) & - & 87 \\
Living in a couple (\%) & French & 66 \\
Living with a child under the age of fourteen & & 30 \\
Individual education (\%) & & 25 \\
& High & 17 \\
& Middle-High & 29 \\
& Middle-Low & 30 \\
Household income per consumption unit $(\%)$ & Low & 33 \\
& High $(>2125 €$ per month) \\
& Medium $(1222-2125 €$ per month) & 34 \\
Employment status $(\%)$ & Low (<1222 $€$ per months) & 33 \\
& & 57 \\
Location in the region $(\%)$ & Stable & 7 \\
& Unstable & 10 \\
& Unemployed & 21 \\
& Retired & 26 \\
& & 46 \\
\hline
\end{tabular}


Table 3. Size (SD) of the exposure areas sequentially incorporating additional types of locations visited (the RECORD Cohort study, 2011-2013)

\begin{tabular}{llll}
\hline Models & $\begin{array}{l}\text { Mean area } \\
\left(\mathrm{km}^{2}\right)\end{array}$ & SD & $\begin{array}{l}\text { \% of area added } \\
\text { compared to the } \\
\text { residential } \\
\text { neighborhood }\end{array}$ \\
\hline Model B & & 0.6 & - \\
Model C & 2.0 & 1.1 & 33.3 \\
Model D & 3.0 & 0.6 & 9.1 \\
Model E & 2.2 & 0.8 & 16.7 \\
Model F & 2.4 & 0.8 & 20.0 \\
Model G & 2.5 & 1.3 & 47.4 \\
\hline
\end{tabular}

${ }^{\mathrm{I}}$ Environmental measures based on the residential neighborhood

${ }^{2}$ Environmental measures based on the residential neighborhood and the work space

${ }^{3}$ Environmental measures based on the residential neighborhood and the service space

${ }^{4}$ Environmental measures based on the residential neighborhood and the recreational space

${ }^{5}$ Environmental measures based on the residential neighborhood and the social space

${ }^{6}$ Environmental measures based on the full activity space 
Table 4. Association between individual and environmental characteristics and not reporting any recreational walking (zero-inflation part) (the RECORD Cohort study, 2011-2013)

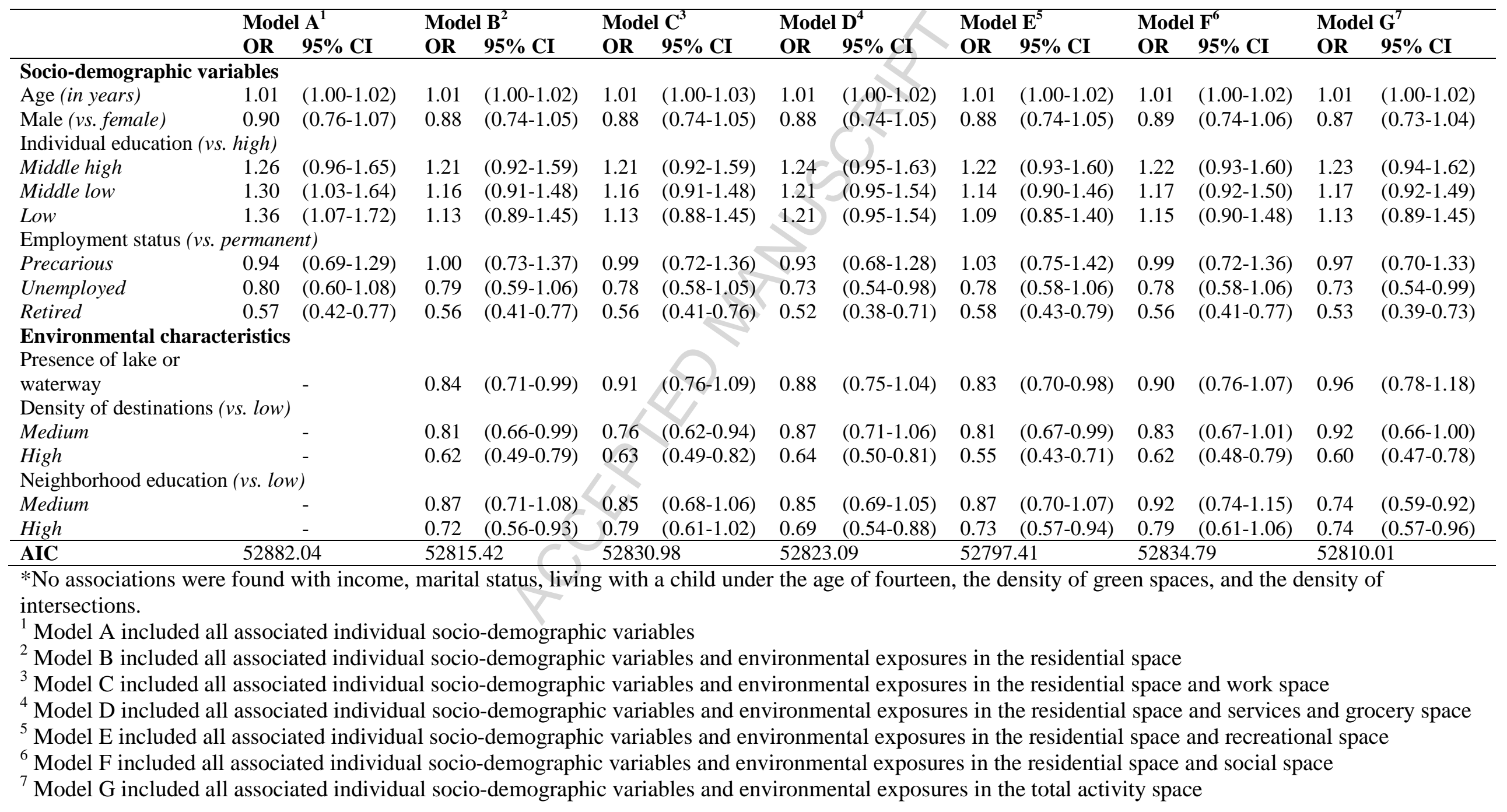


Table 5. Association between individual and environmental characteristics and the recreational walking time among walkers (count part), (the RECORD Cohort study, 2011-2013)

\begin{tabular}{|c|c|c|c|c|c|c|c|c|c|c|c|c|c|c|}
\hline & \multicolumn{2}{|c|}{$\operatorname{Model}^{1}$} & \multicolumn{2}{|c|}{ Model B $^{2}$} & \multicolumn{2}{|c|}{ Model C ${ }^{3}$} & \multicolumn{2}{|c|}{ Model D $^{4}$} & \multicolumn{2}{|c|}{ Model E ${ }^{5}$} & \multicolumn{2}{|c|}{ Model F $^{6}$} & \multicolumn{2}{|c|}{ Model $\mathbf{G}^{7}$} \\
\hline & $\mathbf{P C}^{8}$ & $95 \% \mathrm{CI}$ & PC & $95 \% \mathrm{CI}$ & PC & $95 \% \mathrm{CI}$ & PC & $95 \% \mathrm{CI}$ & PC & $95 \% \mathrm{CI}$ & PC & $95 \% \mathrm{CI}$ & PC & $95 \% \mathrm{CI}$ \\
\hline \multicolumn{15}{|l|}{ Socio-demographic variables } \\
\hline Age (in years) & $+0 \%$ & $(-1 \%,+0 \%)$ & $+0 \%$ & $(-1 \%,+0 \%)$ & $+0 \%$ & $(-1 \%,+0 \%)$ & $+0 \%$ & $(-1 \%,+0 \%)$ & $+0 \%$ & $(-1 \%,+0 \%)$ & $+0 \%$ & $(-1 \%,+0 \%)$ & $+0 \%$ & $(-1 \%,+0 \%)$ \\
\hline Male (vs. female) & $+9 \%$ & $(+3 \%,+16 \%)$ & $+10 \%$ & $(+4 \%,+17 \%)$ & $+10 \%$ & $(+4 \%,+17 \%)$ & $+10 \%$ & $(+4 \%,+17 \%)$ & $+10 \%$ & $(+4 \%,+17 \%)$ & $+10 \%$ & $(+4 \%,+17 \%)$ & $+10 \%$ & $(+4 \%,+17 \%)$ \\
\hline Individual education (vs. high) & & & & & & & & & & & & & & \\
\hline Middle high & $+9 \%$ & $(+0 \%,+19 \%)$ & $+9 \%$ & $(+0 \%,+19 \%)$ & $+10 \%$ & $(+1 \%,+20 \%)$ & $+10 \%$ & $(+1 \%,+20 \%)$ & $+10 \%$ & $(+1 \%,+20 \%)$ & $+10 \%$ & $(+1 \%,+20 \%)$ & $+10 \%$ & $(+1 \%,+20 \%)$ \\
\hline Middle low & $+11 \%$ & $(+3 \%,+20 \%)$ & $+12 \%$ & $(+4 \%,+21 \%)$ & $+13 \%$ & $(+4 \%,+21 \%)$ & $+13 \%$ & $(+5 \%,+22 \%)$ & $+13 \%$ & $(+5 \%,+22 \%)$ & $+13 \%$ & $(+4 \%,+22 \%)$ & $+13 \%$ & $(+5 \%,+22 \%)$ \\
\hline Low & $+19 \%$ & $(+11 \%,+29 \%)$ & $+22 \%$ & $(+13 \%,+32 \%)$ & $+23 \%$ & $(+14 \%,+32 \%)$ & $+23 \%$ & $(+14 \%,+32 \%)$ & $+24 \%$ & $(+15 \%,+33 \%)$ & $+23 \%$ & $(+14 \%,+33 \%)$ & $+24 \%$ & $(+15 \%,+34 \%)$ \\
\hline \multicolumn{15}{|l|}{ Employment status (vs. permanent) } \\
\hline Precarious & $+26 \%$ & $(+13 \%,+40 \%)$ & $+22 \%$ & $(+10 \%,+36 \%)$ & $+25 \%$ & $(+12 \%,+39 \%)$ & $+22 \%$ & $(+10 \%,+36 \%)$ & $+21 \%$ & $(+9 \%,+35 \%)$ & $+23 \%$ & $(+10 \%,+37 \%)$ & $+23 \%$ & $(+10 \%,+37 \%)$ \\
\hline Unemployed & $+61 \%$ & $(+46 \%,+77 \%)$ & $+60 \%$ & $(+46 \%,+76 \%)$ & $+65 \%$ & $(+50 \%,+82 \%)$ & $+61 \%$ & $(+47 \%,+77 \%)$ & $+61 \%$ & $(+46 \%,+77 \%)$ & $+61 \%$ & $(+49 \%,+77 \%)$ & $+63 \%$ & $(+48 \%,+79 \%)$ \\
\hline Retired & $+45 \%$ & $(+31 \%,+60 \%)$ & $+44 \%$ & $(+30 \%,+80 \%)$ & $+47 \%$ & $(+34 \%,+62 \%)$ & $+44 \%$ & $(+31 \%,+59 \%)$ & $+43 \%$ & $(+29 \%,+57 \%)$ & $+44 \%$ & $(+30 \%,+58 \%)$ & $+46 \%$ & $(+32 \%,+61 \%)$ \\
\hline $\begin{array}{l}\text { Living with a child under the } \\
\text { age of } 14 \text { years }\end{array}$ & $-11 \%$ & $(-17 \%,-5 \%)$ & $-10 \%$ & $(-16 \%,-4 \%)$ & $-10 \%$ & $(-16 \%$ & $-10 \%$ & $(-16 \%,-4 \%)$ & $-9 \%$ & $(-15 \%,-3 \%)$ & $-9 \%$ & $(-15 \%,-3 \%)$ & $-9 \%$ & $(-15 \%,-3 \%)$ \\
\hline \multicolumn{15}{|l|}{ Environmental characteristics } \\
\hline Medium & & - & $+14 \%$ & $(+7 \%,+22 \%)$ & $+14 \%$ & $(+7 \%,+22 \%)$ & $+5 \%$ & $(-2 \%,+13 \%)$ & $+13 \%$ & $(+5 \%,+21 \%)$ & $+7 \%$ & $(+0 \%,+15 \%)$ & $+7 \%$ & $(+0 \%,+14 \%)$ \\
\hline High & & - & $+22 \%$ & $(+14 \%,+31 \%)$ & $+20 \%$ & $(+12 \%,+28 \%)$ & $+19 \%$ & $(+11 \%,+28 \%)$ & $+25 \%$ & $(+16 \%,+33 \%)$ & $+19 \%$ & $(+11 \%,+27 \%)$ & $+23 \%$ & $(+15 \%,+31 \%)$ \\
\hline Dispersion & 0.71 & $(0.68-0.74)$ & 0.71 & $(0.68-0.74)$ & 0.71 & $(0.68-0.74)$ & 0.71 & $(0.68-0.74)$ & 0.71 & $(0.68-0.74)$ & 0.71 & $(0.68-0.74)$ & 0.69 & $(0.66-0.72)$ \\
\hline AIC & 52882 & & 52815 & & 52830. & 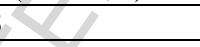 & 52823.0 & & 52797 & & 52834 & & 52810 & \\
\hline
\end{tabular}

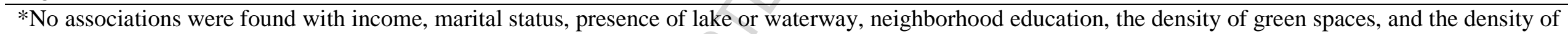
intersections.

${ }^{1}$ Model A included all associated individual socio-demographic variables

${ }^{2}$ Model B included all associated individual socio-demographic variables and environmental exposures in the residential space

${ }^{3}$ Model C included all associated individual socio-demographic variables and environmental exposures in the residential space and work space

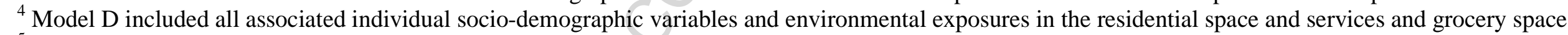

${ }^{5}$ Model E included all associated individual socio-demographic variables and environmental exposures in the residential space and recreational space

${ }^{6}$ Model F included all associated individual socio-demographic variables and environmental exposures in the residential space and social space

${ }^{7}$ Model $\mathrm{G}$ included all associated individual socio-demographic variables and environmental exposures in the total activity space

${ }^{8}$ Percentage change 
Figure 1. Representation of the different portions of the activity space of one participant of the RECORD Cohort residing in the inner suburb of the Ile-de-France region (the RECORD Cohort study, 2011-2013)

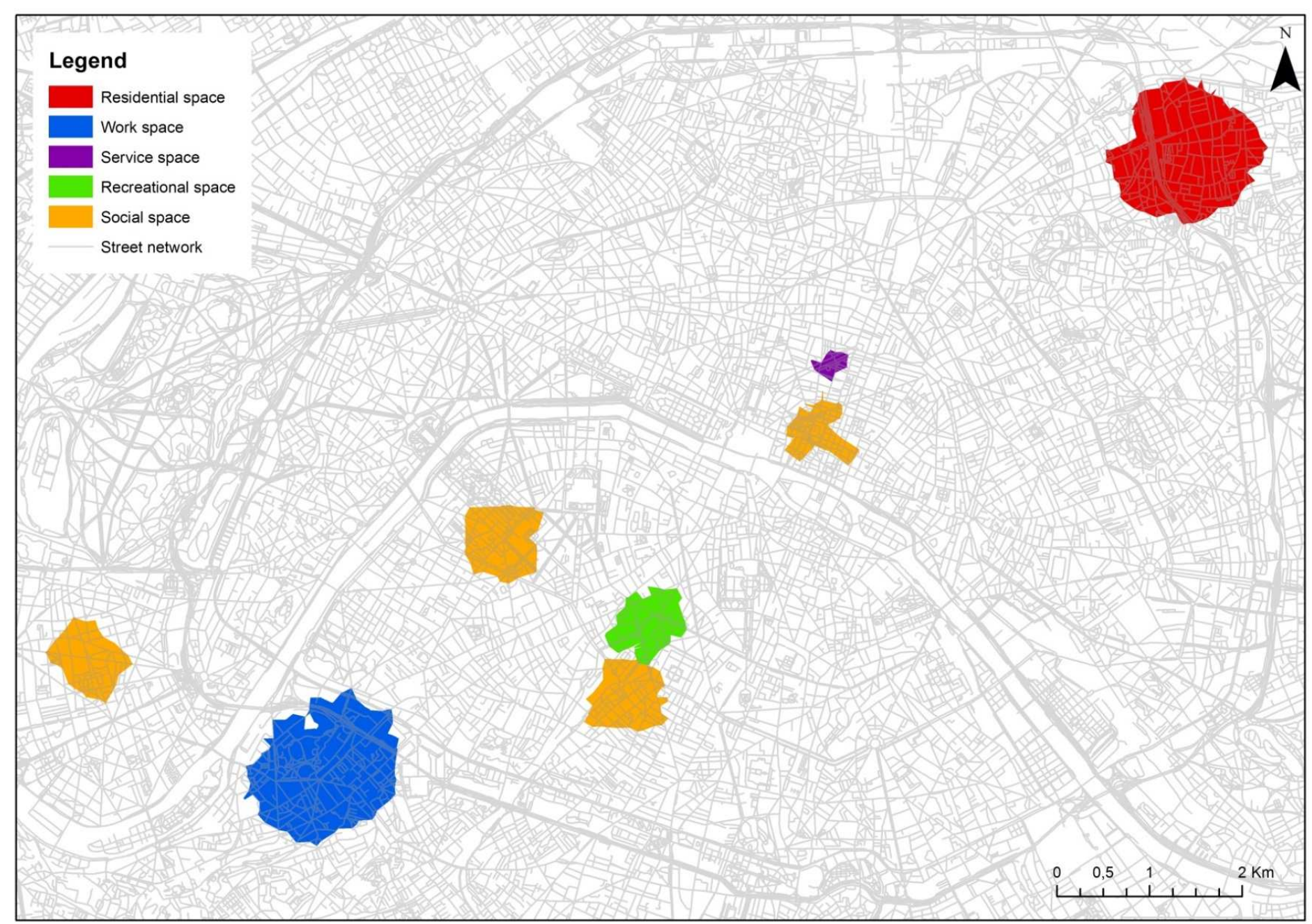




\section{HIGHLIGHTS}

We examined the environmental correlates of recreational walking in a French city

We explored the contributions of different portions of the activity space on walking

High density of destinations and waterway, and high-education areas supported walking Only the density of destination was associated with time spent walking

Accounting for residential and recreational visited locations improved the model fi 


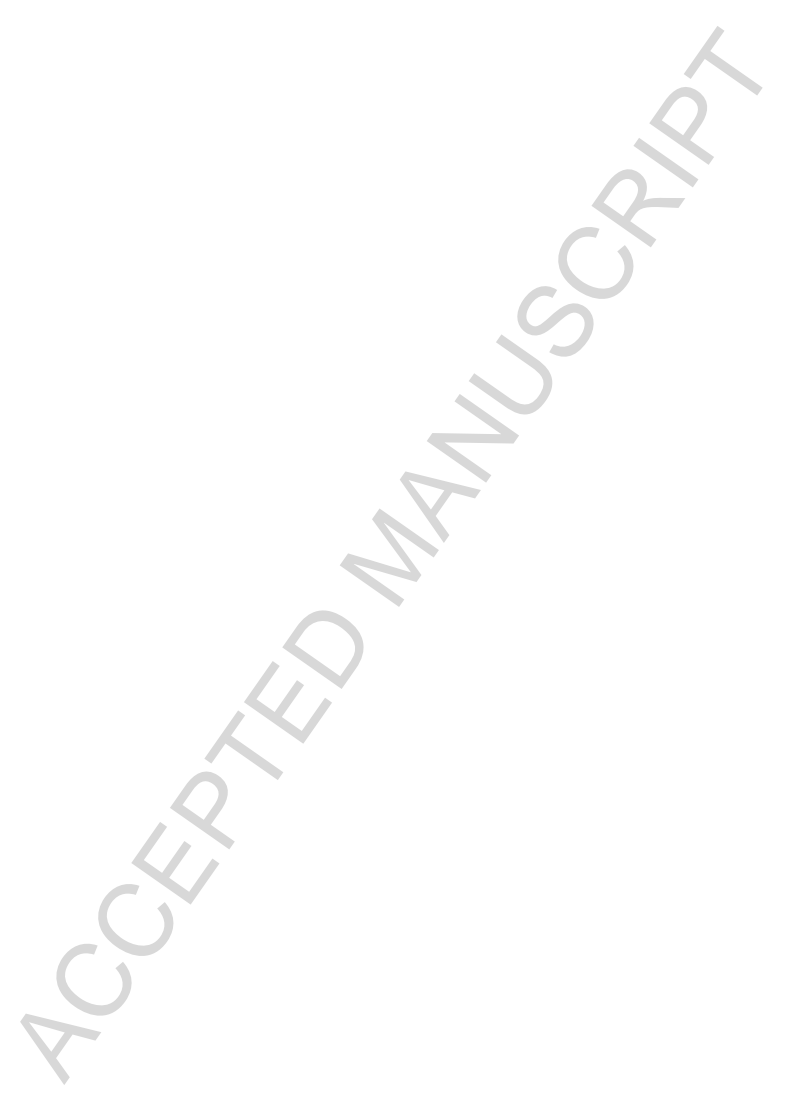

